\title{
Exploiting mechanism-informed phenotypic screening for development of next-generation antimitotic phytochemicals
}

\author{
Namrta Choudhry ${ }^{1,2 *}$, Thaddeus David Allen ${ }^{1,2 *}$, Vidhula Ahire ${ }^{1,2}$, Jing Zhang ${ }^{1,2}$ and Dun Yang $^{1,2}$ \\ ${ }^{1}$ Anticancer Bioscience, Ltd., China \\ ${ }^{2}$ The J. Michael Bishop Institute of Cancer Research, Chengdu 640000, China
}

\section{Introduction}

Abrogation of mitosis is an extremely competent rationale for anticancer treatment [1]. Some natural products (NPs) work by targeting the mitotic regulatory machinery thereby restraining the efficacy of the mitotic spindle, blocking the cell division process and pushing the cells to apoptosis. Hence, NPs that hinder the advancement of mitosis are the most sought after chemotherapeutics, currently. These natural antimitotic products and their derivatives are referred to as spindle poisons/ toxins, are among the most frequently used anti-cancer drugs globally e.g. Vinca alkaloids (vincristine, vinblastine) and taxanes (e.g. paclitaxel, docetaxel). In the past, a variety of drugs that target microtubules and hampers the utility of the mitotic spindle have been used clinically for managing a wide range of human malignancies. Conversely, due to severe undesirable mechanism-based cytotoxicity in the CNS and therapeutic resistance which are repetitively seen at the time of microtubule-targeting, the use of these drugs is limited [1-4]. The new generation of mitotic drugs aims for the mitotic regulatory machinery which involves the motor proteins, mitotic kinesins, or the Aurora and polo-like kinases and complexes which are expressed only at the time of cell division [2]. Research efforts are intended towards developing superior antimitotic drugs that would not be only more specific in their action but would also lessen the burden of side effects on patients. Also, because cancer cells demonstrate vast phenotypic miscellany they are characteristically responsive to phenotypic screening which would assist in translating the molecular mechanism as a therapeutic approach in treating cancer with familiar cellular phenotypes following the theory of mechanism-informed phenotypic screening.

Keywords: phenotypic screening, high-content screening, antimitotic activity, spindle toxins, CPP complex, polyploidy, corynoline, acetylcorynoline

\section{Natural products as the spindle toxins for anticancer drug development}

It has been observed that a slight modification in the dynamics of the microtubule can activate the spindle checkpoint and arrest the progression of the cell cycle in the mitotic phase, the outcome of which is cell death. Our improved knowledge on understanding the mechanism of the targets of the microtubule agents has assisted in modifying the anti-cancer treatment regime [5]. A restraining the microtubule dynamics and killing tumor cells seems to be a common mechanism of drugs that impede mitosis. Cancer cells are comparatively sensitive to such drugs when compared to normal cells for the reason that they segregate faster than normal cells. As a consequence cancer cells pass through the phase of susceptibility to mitotic poisons [6].

Curcumin-induced $\mathrm{G}_{2} / \mathrm{M}$ transition and mitotic cell arrest was seen in eight colorectal cancer cell lines. It acted by disrupting the primary events of mitosis, like the centrosome segregation, chromosomal alignment at the equator and bipolar spindle assembly [7]. Vinca alkaloids impair mitotic spindles at high concentrations (10-100 $\mathrm{nM})$ in HeLa cells and depolymerize microtubules [8], consequently leaving the dividing cancer cells stalled in mitosis with condensed chromosomes [5]. Paclitaxel instigates the cellular mitosis by activating the mitotic checkpoint/spindle assembly checkpoint, which is the key cell cycle control mechanism acting during mitosis to avert errors in chromosome segregation [9]. Combretastatins display cytotoxic properties and prohibition of tubulin polymerization in vitro in cancer cells [10]. These are beneficial classes of compounds compared to anti-mitotic agents as they also act as angiogenesis inhibitors and are known as vascular disrupting agents $[11,12]$. Epothilones A and B [13] are a new class of MTAs, securing the microtubules and inhibiting the dynamic behavior of microtubules at the mitotic spindle and, thus, holding back cancer cells from mitosis. Despite their widespread use as chemotherapeutics, these drugs exert significant mechanism-based cytotoxicity in the central nervous system and therapeutic resistance often develops $[14,15]$. To optimize efficacy, while minimizing the undesired effects of spindle toxins, research and development have also focused on specific drug delivery systems or delivery of pro-drugs to cancer cells.

As an alternative to the tubulin-binding spindle toxins, some compounds exhibit anti-cancer therapeutic efficacy inhibiting the activity of kinases which are crucial for mitotic progression. When compared to spindle toxins this approach looks more promising to avoid cellular toxicity. Mitotic inhibitors have been developed for about a dozen of mitotic regulators. Despite some of them having

${ }^{*}$ Correspondence to: Namrta Choudhry and Thaddeus David Allen, The J Michael Bishop Institute of Cancer Research, Chengdu 640000, China, E-mail: namrta.choudhry@mbicr.org / thaddeus.allen@mbicr.org

Key words: phenotypic screening, high-content screening, antimitotic activity, spindle toxins, CPP complex, polyploidy, corynoline, acetylcorynoline

Received: December 03, 2020; Accepted: January 02, 2021; Published: January 06,2021 
been tested in clinical trials, the clinical breakthrough in this field is still forthcoming [16-18]. Synthetic small molecules dominate the landscape of potential inhibitors of mitotic regulators, while there is an under-representation of (NP) compounds that are non-spindle toxin anti-mitotic regulators. Recently, there has been a growing interest in the application of novel screens for phytochemicals with the ability to disrupt cancer cell mitosis [19].

\section{Mechanism-informed phenotypic screening for natural products that mimic inhibition of the Chromosomal Passenger Protein (CPP) Complex}

For the past three decades, anticancer drugs have mainly been developed with a predetermined target in mind. However, phenotypic screening (PS) programs for anticancer compounds have increased adequately. This may be a less biased approach in that expectation of hitting one target, in particular, is absent. Since a positive hit is solely dependent on observed phenotype, PS of cellular assays (or sometimes organismal) can reveal inhibitors of novel targets that may be upstream of a desired phenotype [20]. This can be important when one does not know much about the assayed disease pathway. Various studies have been published on PS, documenting its advantages over target-based screening studies [21-23]. In this commentary, we discuss a recently published study [19] that highlights the potential of mechanisminformed, phenotypic screening for uncovering antimitotic activity in libraries' natural compounds. The study describes a unique imagebased, high-throughput screening (HTS) bioassay to identify NPs that can mimic inhibition of the chromosomal passenger protein (CPP) complex in eliciting cell division defects [19].

Identified active antimitotic compounds

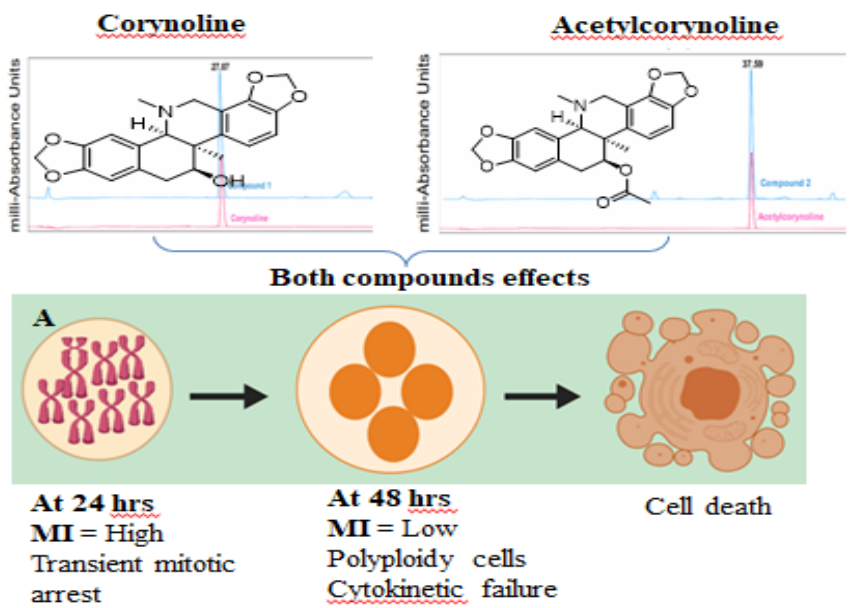

Acquisitions of desired phenotypes

C Proposed mechanism of action (MOA)

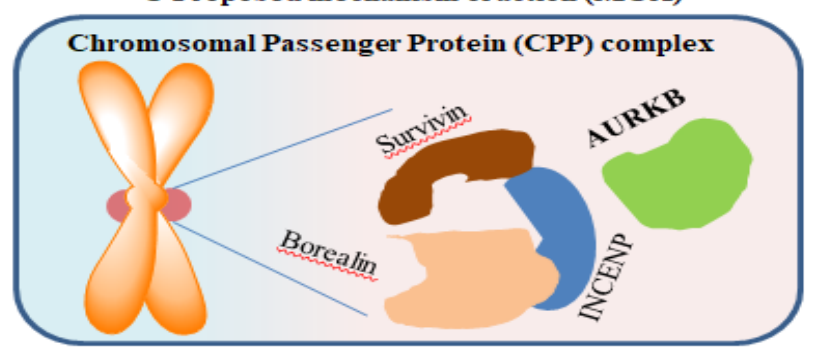

The CPP complex is composed of the Aurora B serine/threonine kinase subunit (AURKB), the inner centromere scaffold protein, INCENP (Inner Centromere Protein), and two small regulatory components, survivin and borealin (also known as Dasra) [24-25]. The CPP complex is essential to ensure accuracy in chromosome segregation, maintenance of the spindle checkpoint response and completion of cytokinesis. Two components of the CPP in particular, AURKB and survivin, have received attention as targets for novel anti-cancer therapeutics [26]. This attention stemmed from their overexpression in a variety of human malignancies and ability to facilitate tumorigenesis in model systems [27]. Disabling the CPP complex in cancer cells can produce pleiotropic cell division defects, apoptosis, and lethal autophagy [28-30] and cells overexpressing the MYC oncogene have proven particularly susceptible to disabling the CPP. MYC-synthetic lethal drug interactions are an attractive and active area of investigation as MYC, a transcription factor has proven refractory to direct inhibition with small molecules [31].

Li et al. [19] performed their image-based HTS with a prior understanding of the versatile functions of the CPP complex in orchestrating karyokinesis and cytokinesis. They specifically scored for phenotypes that mimic those seen when the CPP complex is disabled in a drug-sensitive cell line. The parameters for a positive hit were an elevation of mitotic index (MI) at 24 hours of drug treatment, indicative of arrest, and an accumulation of polyploid cells at 48 hours of drug treatment, indicative of cytokinetic failure. With the knowledge that both phenotypes ensue from inhibition of the CPP, the researchers could exclude compounds that elicited only a prolonged arrest of cells in mitosis, a phenotype typically provoked by spindle toxins. Visualization

Figure 1: Displaying the comparative phenotypes: A) with corynoline and acetylcorynoline treatment B) with spindle toxins treatment C) Proposed mechanism of action by both compounds. 
of mitotic cells and polyploidy was conveniently facilitated by the engineered expression of $\mathrm{H} 2 \mathrm{~B}-\mathrm{GFP}$ fusion proteins in their screening cell line. After screening a large NP library of 17,000 extracts from $>2,000$ plants, they identified activity mimicking CPP inhibition in an extract from C. longicalcarata. Bioassay-guided isolation and purification processes were used to identify active components as corynoline and its derivative acetylcorynoline.

\section{Phytochemicals that mimics inhibition of the CPP complex}

Both corynoline and acetylcorynoline are known phytochemicals that have been previously isolated from Corydalis incisa (family Papaveraceae; IPNI: 672291-1) [32] and Corydalis bungeana (family Papaveraceae; IPNI: 672108-1) [33-34]. They are known to stimulate a variety of pharmacological activities [35-38], but no antimitotic activity has been described. With the recent descriptions, we can now ascribe antimitotic and polyploidy-inducing activity to these phytochemicals, dramatizing the promise of mechanism-informed phenotypic screening in uncovering alternative antimitotic compounds for cancer therapy and the novel biology activity for known phytochemicals, in general. Unlike spindle toxins (taxoids and Vinca alkaloids), which induce a prolonged mitotic arrest and eventually apoptosis of cancer cells, corynoline and acetylcorynoline failed to permanently arrest cells in mitosis. Instead, both compounds elevated mitotic index through a transient arrest of cells in prometaphase, and ultimately induced polyploidy by preventing cytokinesis (Figure A \& B). These cell division defects are similar to those seen when the CPP complex is disabled (Figure C). However, the catalytic activity of the CPP complex was not affected by these compounds. It is still possible that they may interfere with the localization of the CPP complex or a component downstream of the complex. Even though the mitotic target for these phytochemicals is still mysterious, they have excellent lead-like properties that warrant investigation as a new scaffold for modification of more potent and drug-like leads that could be antimitotic agents for the treatment of human cancer that lack the toxic effects associated with currently used antimitotic.

\section{Conclusions and future perspective}

Targeting cancerous cells when they are most vulnerable during mitosis has instigated several studies into the mitotic cell death pathway. Therefore, NPs targeting microtubules and disrupting the normal functioning of the mitotic spindles are the finest class of chemotherapeutics offered in the clinics. Although, traditional antimitotic agents, such as taxanes and the vinca alkaloids, have been used clinically for decades, the unpredictable complexities of patient's response to these drugs still pose a leading challenge for its clinical success. Additionally, drug resistance and toxicity also need to be addressed. A new generation of anti-mitotic drugs that work through a distinct mechanism of action, may overcome these limitations. The work described here focused on novel screening methods to find a new generation of antimitotic compounds that work through distinct mechanisms. It appears that corynoline and acetylcorynoline interfere with mitotic regulators, mimicking the CPP complex, rather than through the disruption of microtubules. The development of these compounds as scaffolds for modifications may yield molecules that are potent and safe antimitotic therapeutics. It is the need of time to explore more and more novel natural antimitotic agents which demonstrate the possibility to evade the challenges associated with antimitotic therapy.

\section{References}

1. Kaestner P, Bastians H (2010) Mitotic drug targets. J Cell Biochem 111: 258-265. [Crossref]
2. Schmidt M, Bastians H (2007) Mitotic drug targets and the development of novel antimitotic anticancer drugs. Drug Resist 10: 162-181. [Crossref]

3. Paier CRK, Maranhão SSA, Carneiro TR, Lima LM, Rocha DD, et al. (2018) Natural products as new antimitotic compounds for anticancer drug development. Clinics (SaO Paulo) 73: e813s. [Crossref]

4. Kavallaris M, Verrills NM, Hill BT (2001) Anticancer therapy with novel tubulininteracting drugs. Drug Resist 4: 392-401. [Crossref]

5. Mukhtar E, Adhami VM, Mukhtar H (2014) Targeting microtubules by natural agents for cancer therapy. Mol Cancer Ther 13: 275-284. [Crossref]

6. Shelby RD, Hahn KM, Sullivan KF (1996) Dynamic elastic behavior of $\alpha$-satellite DNA domains visualized in situ in living human cells. $J$ Cell Biol 135 :545-557. [Crossref]

7. Blakemore LM, Boes C, Cordell R, Manson MM (2013) Curcumin-induced mitotic arrest is characterized by spindle abnormalities, defects in chromosomal congression and DNA damage. Carcinogenesis 34: 351-360. [Crossref]

8. Jordan MA, Wilson L (2004) Microtubules as a target for anticancer drugs. Nat Rev Cancer 4: 253-265. [Crossref]

9. Weaver BA (2014) How Taxol/paclitaxel kills cancer cells. Mol Biol Cell 25: 2677 2681. [Crossref]

10. Pettit GR, Singh SB, Hamel E, Lin CM, Alberts DS, et al. (1989) Isolation and structure of the strong cell growth and tubulin inhibitor combretastatin A-4. Experientia 45: 209211. [Crossref]

11. Siemann DW, Chaplin DJ, Walicke PA (2009) A review and update of the current status of the vasculature-disabling agent combretastatin-A4 phosphate (CA4P). Expert Opin Investig Drugs 18: 189-197. [Crossref]

12. Griggs J, Metcalfe JC, Hesketh R (2001) Targeting tumour vasculature: The development of combretastatin A4. Lancet Oncol 2: 82-87. [Crossref]

13. Gerth K, Bedorf N, Höfle G, Irschik H, Reichenbach H (1996) Epothilons A and B Antifungal and cytotoxic compounds from Sorangium cellulosum (Myxobacteria) production, physico-chemical and biological properties. J Antibiot (Tokyo) 49: 560563. [Crossref]

14. Campos SM, Dizon DS (2012) Antimitotic Inhibitors. Hematol Oncol Clin North Am 26: 607-628. [Crossref]

15. Gascoigne KE, Taylor SS (2009) How do anti-mitotic drugs kill cancer cells? J Cell Sci 122: 2579-2585. [Crossref]

16. Vermeulen K, Van Bockstaele DR, Berneman ZN (2003) The cell cycle: A review of regulation, deregulation and therapeutic targets in cancer. Cell Prolif 36: 131-149. [Crossref]

17. Deep G, Agarwal R (2008) New combination therapies with cell-cycle agents. Curr Opin Investig Drugs 9: 591-604. [Crossref]

18. Dominguez-Brauer C, Thu KL, Mason JM, Blaser H, Bray MR, et al. (2015) Molecular Cell Review Targeting Mitosis in Cancer: Emerging Strategies. Mol Cell 60: 524-536. [Crossref]

19. Li J, Yan Z, Li H, Shi Q, Huang L, et al. (2019) Purification, identification, and characterization of two benzophenanthridine alkaloids from Corydalis longicalcarata rhizomes with anti-mitotic and polyploidy-inducing activities. BioRxiv 821124.

20. Eggert US (2013) The why and how of phenotypic small-molecule screens. Nat Chem Biol 9: 206-209. [Crossref]

21. Eder J, Sedrani R, Wiesmann C (2014) The discovery of first-in-class drugs: Origins and evolution. Nat Rev Drug Discov 13: 577-587. [Crossref]

22. Aulner N, Danckaert A, Ihm JE, Shum D, Shorte SL (2019) Next-Generation Phenotypic Screening in Early Drug Discovery for Infectious Diseases. Trends Parasitol 35: 559570. [Crossref]

23. Vincent F, Loria P, Pregel M, Stanton R, Kitching L, et al (2015) Developing predictive assays: The phenotypic screening "rule of 3." Sci Transl Med 7: 293ps15. [Crossref]

24. Van Der Horst A, Lens SMA (2014) Cell division: Control of the chromosomal passenger complex in time and space. Chromosoma 123: 25-42. [Crossref]

25. Zhang J, Zhang S, Shi Q, Yang D, Allen TD (2020) Pro-survival Bcl-2 Proteins are Modifiers of MYC-VX-680 Synthetic Lethality. J Cell Immunol 2: 5. [Crossref]

26. Girdler F, Gascoigne KE, Eyers PA, Hartmuth S, Crafter C, et al. (2006) Validating Aurora B as an anti-cancer drug target. J Cell Sci 119: 3664-3675. [Crossref] 
27. Carvajal RD, Tse A, Schwartz GK (2006) Aurora kinases: New targets for cancer therapy. Clin Cancer Res 12: 6869-6875. [Crossref]

28. Andrews PD, Knatko E, Moore WJ, Swedlow JR (2003) Mitotic mechanics: The auroras come into view. Curr Opin Cell Biol 15: 672-683. [Crossref]

29. Carmena M, Earnshaw WC (2003) The cellular geography of Aurora kinases. Nat Rev Mol Cell Biol 4: 842-854. [Crossref]

30. Keen N, Taylor S (2004) Aurora-kinase inhibitors as anticancer agents. Nat Rev Cancer 4: 927-936. [Crossref]

31. Chen H, Liu H, Qing G (2018) Targeting oncogenic Myc as a strategy for cancer treatment. Signal Transduct Target Ther 3: 5. [Crossref]

32. Naruto S, Arakawa S, Kaneko H (1968) Conformational analysis of corynoline and its related compounds. Tetrahedron Lett 14: 1705-1709. [Crossref]

33. Ma WG, Fukushi Y, Tahara S (1999) Fungitoxic alkaloids from Hokkaido Corydalis species. Fitoterapia 70: 258-265. [Crossref]
34. Wang X, Dong H, Shu X, Zheng Z, Yang B, et al. (2012) Large-Scale Separation of Alkaloids from Corydalis bungeana Turcz. by pH-Zone-Refining Counter-Current Chromatography. Molecules 17: 14968-14974. [Crossref]

35. Choi SU, Baek NI, Kim SH, Yang JH, Eun JS, et al. (2007) Cytotoxic isoquinoline alkaloids from the aerial parts of Corydalis incisa. Arch Pharm Res 30: 151-154. [Crossref]

36. Chlebek J, De Simone A, Hoš́álková A, Opletal L, Pérez C, et al.(2016) Application of BACE1 immobilized enzyme reactor for the characterization of multifunctional alkaloids from Corydalis cava (Fumariaceae) as Alzheimer's disease targets. Fitoterapia 109: 241-247. [Crossref]

37. Dong ZB, Zhang YH, Zhao BJ, Li C, Tian G, et al. (2015) Screening for antiinflammatory components from Corydalis bungeana Turcz. based on macrophage binding combined with HPLC. BMC Complement Altern Med 15: 363. [Crossref]

38. Kamigauchi M, Noda Y, Nishijo J, Iwasaki K, Tobetto K, et al. (2005) Cell adhesion inhibitory activity of (d)-corynoline, a hexahydrobenzo[c] phenanthridine-type alkaloid, and its structure-activity relationship, studied by X-ray crystal structure analysis and molecular docking study. Bioorganic Med Chem 13: 1867-1872. [Crossref]

Copyright: ( $\odot 2021$ Choudhry N. This is an open-access article distributed under the terms of the Creative Commons Attribution License, which permits unrestricted use, distribution, and reproduction in any medium, provided the original author and source are credited. 